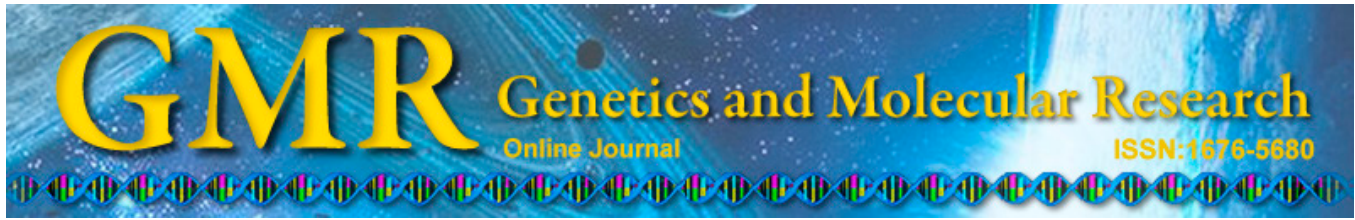

\title{
Nineteen polymorphic microsatellite markers developed for Trachinotus ovatus
}

\author{
Z.Z. Xie ${ }^{1}$, M.W. Huang ${ }^{1}$, W. Xu ${ }^{1}$, C. Peng ${ }^{1}$, J.N. He ${ }^{1}$ Z.N. Meng ${ }^{1}$, \\ Y. Zhang ${ }^{1}$, S.S. Li ${ }^{1}$ and H.R. Lin ${ }^{1,2}$
}

${ }^{1}$ State Key Laboratory of Biocontrol, Institute of Aquatic Economic Animals, and the Guangdong Province Key Laboratory for Aquatic Economic Animals, Sun Yat-Sen University, Guangzhou, China

${ }^{2}$ College of Ocean, Hainan University, Haikou, China

Corresponding author: S.S. Li

E-mail: 1shuish@mail.sysu.edu.cn

Genet. Mol. Res. 13 (4): 10518-10522 (2014)

Received November 25, 2013

Accepted March 6, 2014

Published December 12, 2014

DOI http://dx.doi.org/10.4238/2014.December.12.13

\begin{abstract}
To evaluate the population genetic diversity of the ovate pompano, we isolated and characterized 19 microsatellite markers using a (CA) ${ }_{13}$-enriched genomic library. Polymorphism was assessed in 30 individuals from a single population collected from the Daya Bay Aquaculture Center, Guangdong, China. The number of alleles per locus ranged from 2 to 18 with an average of 7.8. The observed and expected heterozygosities varied from 0.2667 to 1.000 and from 0.3960 to 0.9435 , respectively. Sixteen of 19 loci conformed to HardyWeinberg equilibrium, and no significant linkage disequilibrium was detected between any locus pairs. Our study supplies candidate microsatellite markers that can be useful for studying the population genetic structure of ovate pompano.
\end{abstract}

Key words: Trachinotus ovatus; Microsatellite markers; Genetic structure 


\section{INTRODUCTION}

The ovate pompano Trachinotus ovatus (Teleostei, Carangidae), an economically important marine fish species, is widely distributed in the tropical and subtropical areas of the Indian Ocean, the Pacific Ocean, and the Atlantic Ocean. Because of its delicious flavor, the ovate pompano has always faced strong market demand, which results in the decline of the wild resources of ovate pompano because of overfishing and promotes the artificial culture of the species. Indeed, the ovate pompano has now become one of most commonly cultured marine fish species in Asian-Pacific regions. However, there is little information about the genetic diversity and population structure of this species, which can provide important scientific support for the conservation and sustainable use of the ovate pompano.

In order to provide useful molecular markers to evaluate population genetic diversity and management of stocks of the ovate pompano, this study aimed to isolate and characterize polymorphic microsatellite loci in this species. It has been demonstrated that microsatellite markers are highly polymorphic and widely used in genome mapping and population genetic studies (Litt and Luty, 1989; Shao et al., 2009; Yang et al., 2010). Furthermore, microsatellite markers are also useful for linkage map construction and future molecular marker-assisted breeding of the ovate pompano.

\section{MATERIAL AND METHODS}

To detect the genetic polymorphism of these isolated microsatellite markers, we collected 30 individuals of T. ovatus from the Daya Bay Aquaculture Center, Guangdong, China. The fin of the fresh fish was preserved in $95 \%$ ethanol at $-20^{\circ} \mathrm{C}$ before DNA extraction.

Genomic DNA was extracted from the fin tissues of two unrelated individuals using the standard proteinase $\mathrm{K} /$ phenol extraction method. The microsatellite library was constructed according to the protocol of Zane et al. (2002), with some modifications. A total of $500 \mathrm{ng}$ genomic DNA was digested with MseI restriction enzyme (New England Biolabs, USA) in a $25-\mu \mathrm{L}$ volume. Fragments with a length of 400-1000 bp were isolated from an agarose gel and then ligated to MseI adaptors, oligo A (5'-TACTCAGGACTCAG-3') and oligo B (5'-GACGATGAGTCCTGAG-3'), using T4 DNA ligase (New England Biolabs). The product was subsequently amplified with adaptor-specific primers (5'-GATGAGTCCTGAGTAAN-3', MseI-N) in a total volume of $30 \mu \mathrm{L}$ containing $10.4 \mu \mathrm{L}$ Ex-Taq premix buffer (TaKaRa, Japan), $1 \mu \mathrm{L} 0.4 \mu \mathrm{M}$ MseI-N, $10 \mu \mathrm{L}$ diluted digestion-ligation DNA, and $8.6 \mu \mathrm{L} \mathrm{H}_{2} \mathrm{O}$. Polymerase chain reaction (PCR) amplification was performed as follows: $94^{\circ} \mathrm{C}$ for $5 \mathrm{~min} ; 35$ cycles of $94^{\circ} \mathrm{C}$ for $45 \mathrm{~s}, 55^{\circ} \mathrm{C}$ for $45 \mathrm{~min}$, and $72^{\circ} \mathrm{C}$ for $45 \mathrm{~s}$; and a final extension at $72^{\circ} \mathrm{C}$ for $5 \mathrm{~min}$. The PCR product was purified with the Wizard PCR clean-up system (Promega, USA) and hybridized with $100 \mathrm{nM}$ biotin-labeled (CA) ${ }_{13}$ probe at $68^{\circ} \mathrm{C}$ for $1 \mathrm{~h}$ after $5 \mathrm{~min}$ of denaturation. Streptavidin-coated magnetic beads (Promega) were used to selectively capture sequences containing TG repeats, and later, specific DNA was eluted from the beads by denaturation at $95^{\circ} \mathrm{C}$. The eluted DNA was amplified again 
using the same cycling program as before. After purification using the Wizard PCR cleanup system (Promega), the DNA products were cloned into the pMD18-T vector (TaKaRa) and transformed into Escherichia coli DH5 $\alpha$ competent cells. Transformed cells were plated on lysogeny broth agar containing ampicillin, isopropyl $\beta$-D-1-thiogalactopyranoside, and 5-bromo-4-chloro-3-indolyl- $\beta$-D-galactopyranoside, which is used for blue/white selection, and incubated at $37^{\circ} \mathrm{C}$ for $12 \mathrm{~h}$. Positive clones were randomly selected and sequenced using an ABI PRISM 3730 automated DNA sequencer (Applied Biosystems, USA).

Primer pairs were designed using the PRIMER 3 online software (Rozen and Skaletsky, 2000). These microsatellites were characterized in a sample of 30 individuals collected from Daya Bay Aquaculture Center, Guangdong, China. Genomic DNA of each individual was isolated using the Wizard Genomic DNA Purification kit (Promega). PCR amplification was performed in a $20-\mu \mathrm{L}$ volume containing the following components: $10 \mu \mathrm{L}$ Ex-Taq premix buffer (TaKaRa), $1 \mu \mathrm{M}$ of each primer, and $50 \mathrm{ng}$ template DNA. The PCR conditions were $5 \mathrm{~min}$ at $94^{\circ} \mathrm{C} ; 35$ cycles of $45 \mathrm{~s}$ at $94^{\circ} \mathrm{C}, 40 \mathrm{~s}$ at the annealing temperature for each locus (Table 1), and $40 \mathrm{~s}$ at $72^{\circ} \mathrm{C}$; and a final extension of $5 \mathrm{~min}$ at $72^{\circ} \mathrm{C}$. Amplified products were separated on an $8 \%$ polyacrylamide gel and visualized by silver staining. The size of alleles was identified according to a pBR322/Msp I marker (Tiangen, China). After screening all loci in the population tested, genotypes of polymorphic loci were scored. The expected and observed heterozygosities together with an analysis of Hardy-Weinberg equilibrium (HWE) and linkage disequilibrium were calculated using GENEPOP 4.0 (Raymond and Rousset, 1995). Null allele frequencies were calculated with MICRO-CHECKER 2.2.3 (Van Oosterhout et al., 2004). The significant values for all multiple tests were corrected by the sequential Bonferroni's procedure (Rice, 1989). The polymorphism information content (PIC) was calculated using PIC_CALC 0.6 (http://hi.baidu.com/luansheng1229/item/306815126d58e3a4feded5a4).

\section{RESULTS AND DISCUSSION}

In this study, 19 polymorphic microsatellite loci were successfully isolated from ovate pompano. The average number of alleles per locus was 7.8 and ranged from 2 to 18 . The observed heterozygosity ranged from 0.2667 to 1.000 , and the expected heterozygosity ranged from 0.3960 to 0.9435 , with mean values of 0.6912 and 0.6941 , respectively (Table 1). Of the 19 loci, three loci (EC-11, EC-18, and EC-27) deviated significantly from HWE (P $<0.05$ ) after sequential Bonferroni's correction (adjusted $\mathrm{P}$ value $<0.00158$ ). The observed deviation from HWE was probably due to the presence of null alleles. Pairwise comparisons of loci revealed no linkage disequilibrium after Bonferroni's correction. Among the 19 microsatellite loci, 14 had PIC values that were higher than 0.5, while the PIC values of the other loci were between 0.25 and 0.50 .

With respect to the decline of the wild resource and large-scale mariculture of ovate pompano, it is particularly important to study the population genetic diversity and population structure for its conservation and sustainable use. This study provided 19 novel highly polymorphic microsatellite markers that can be employed to analyze the population genetics of ovate pompano. 


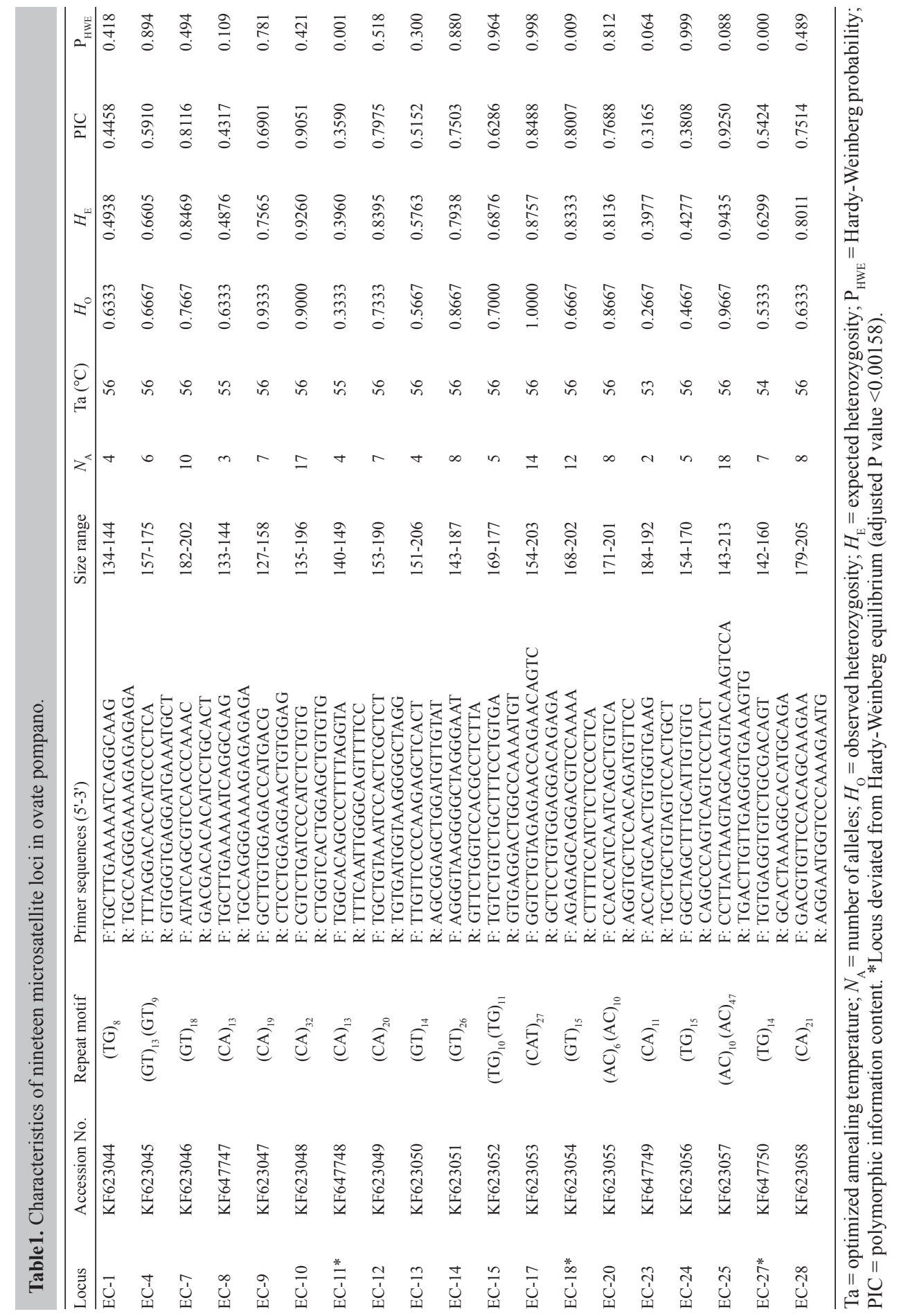




\title{
ACKNOWLEDGMENTS
}

\author{
Research supported by the National "863” Program of China (\#2012AA10A407).
}

\section{REFERENCES}

Litt M and Luty JA (1989). A hypervariable microsatellite revealed by in vitro amplification of a dinucleotide repeat within the cardiac muscle actin gene. Am. J. Hum. Genet. 44: 397-401.

Raymond M and Rousset F (1995). GENEPOP (Version 1.2): population genetics software for exact tests and ecumenicism. J. Hered. 86: 248-249.

Rice WR (1989). Analyzing tables of statistical tests. Evolution 43: 223-225.

Rozen S and Skaletsky HJ (2000). Primer 3 on the WWW for general users and for biologist programmers. Methods Mol. Biol. 132: 365-386.

Shao CW, Liao XL, Tian YS and Chen SL (2009). Microsatellite marker analysis of genetic structures of three populations of cultured Japanese flounder Paralichthys olivaceus. Prog. Fish. Sci. 30: 41-46.

Van Oosterhout C, Hutchinson WF, Wills DPM and Shipley P (2004). MICRO-CHECKER: software for identifying and correcting genotyping errors in microsatellite data. Mol. Ecol. Notes 4: 535-538.

Yang Z, Shi F, Que YF, Xiong MH, et al. (2010). Preliminary studies on genetic diversity of first filial generation of Myxocyprinus asiaticus from artificial propagation releasing in Yangtze River. J. Hydroecol. 3: 17-20.

Zane L, Bargelloni L and Patarnello T (2002). Strategies for microsatellite isolation: a review. Mol. Ecol. 11: 1-16. 